\title{
(POSTER) Automated Media Sweeper for Reducing Media Loss at Yamaha Marine Precision Propeller Facility
}

Kyla Christmas

christmask@uindy.edu

Tyler W. Cole

University of Indianapolis, colet@uindy.edu

Jevis T. Muluh

University of Indianapolis, muluht@uindy.edu

Ryan N. Veazie

University of Indianapolis, veazier@uindy.edu

Paul Talaga

University of Indianapolis, talagap@uindy.edu

See next page for additional authors

Follow this and additional works at: https://docs.lib.purdue.edu/aseeil-insectionconference

Part of the Mechanical Engineering Commons, and the Other Engineering Commons

Christmas, Kyla; Cole, Tyler W.; Muluh, Jevis T.; Veazie, Ryan N.; Talaga, Paul; Ricco, George; Dhamarathne, Suranga; and Cook, Tyler, "(POSTER) Automated Media Sweeper for Reducing Media Loss at Yamaha Marine Precision Propeller Facility" (2019). ASEE IL-IN Section Conference. 5.

https://docs.lib.purdue.edu/aseeil-insectionconference/2019/posters/5 
Presenter Information

Kyla Christmas, Tyler W. Cole, Jevis T. Muluh, Ryan N. Veazie, Paul Talaga, George Ricco, Suranga

Dhamarathne, and Tyler Cook 


\section{Automated Media Sweeper for Reducing Media Loss at Yamaha Marine Precision Propeller Facility}

Kyla Christmas, Tyler Cole, Tyler Cook, Muluh J. Tizie, Ryan Veazie, S. Dharmarathne, G. Ricco, P. Talaga

R.B. Annis School of Engineering; University of Indianapolis, Indianapolis, IN

\section{Introduction and Overview}

Design For Six Sigma (DFSS) project at the University of Indianapolis, a design spine framework in partnership with Yamaha Marine Precision Propellers to reduce the waste of their polishing media.

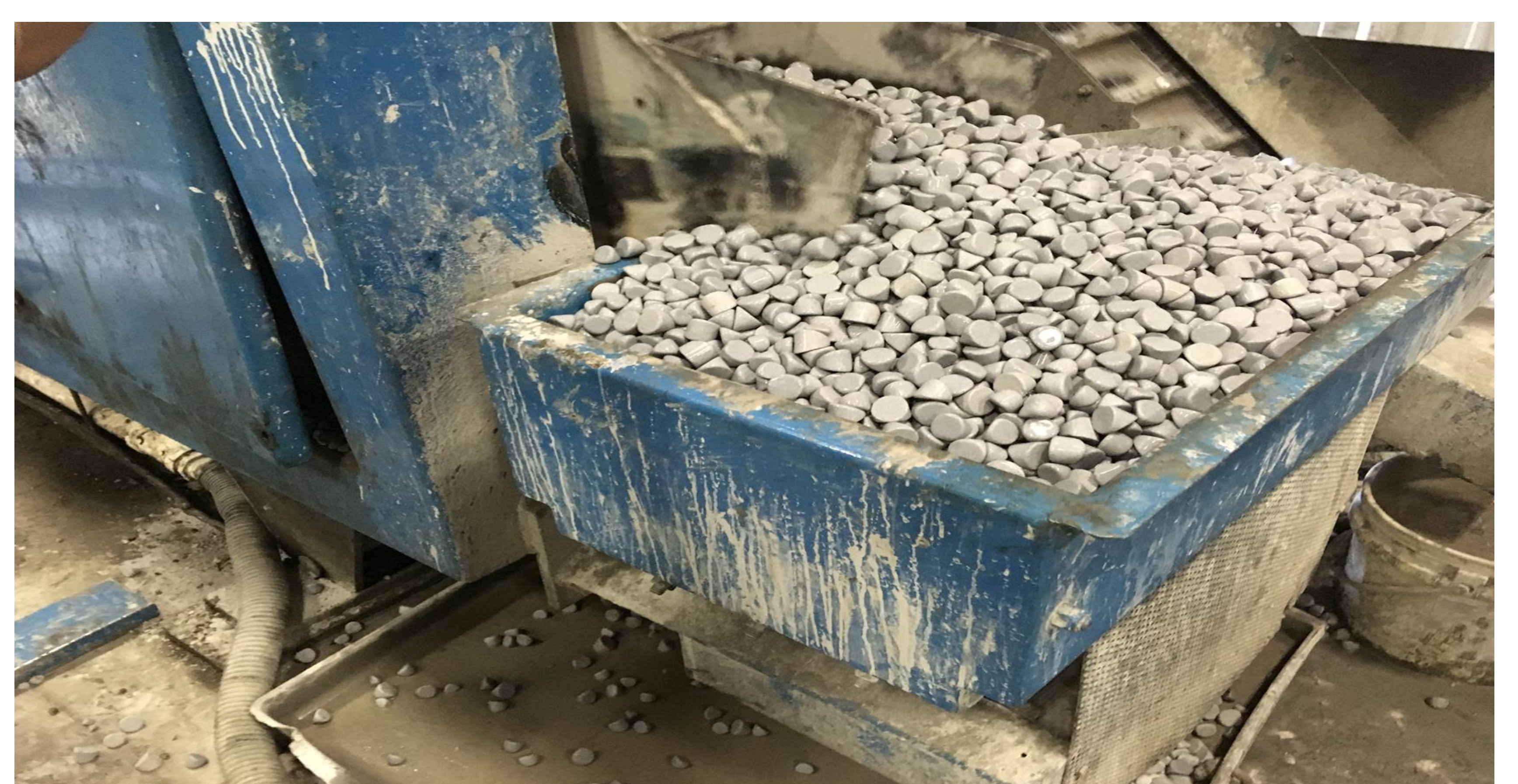

Fig. 1. A view of media falling out of the hopper as the system runs.

\section{Fabricated system}

This system is a device that facilitates the movement of media through the hopper by the use of a revolving arm mechanism. This system is made of an AC Gear motor which will generate movement, the arms to sweep the media out of the hopper and the bracket to keep the whole system attached to the vibratory finisher. There is also an emergency switch to stop the system in case it malfunctions.

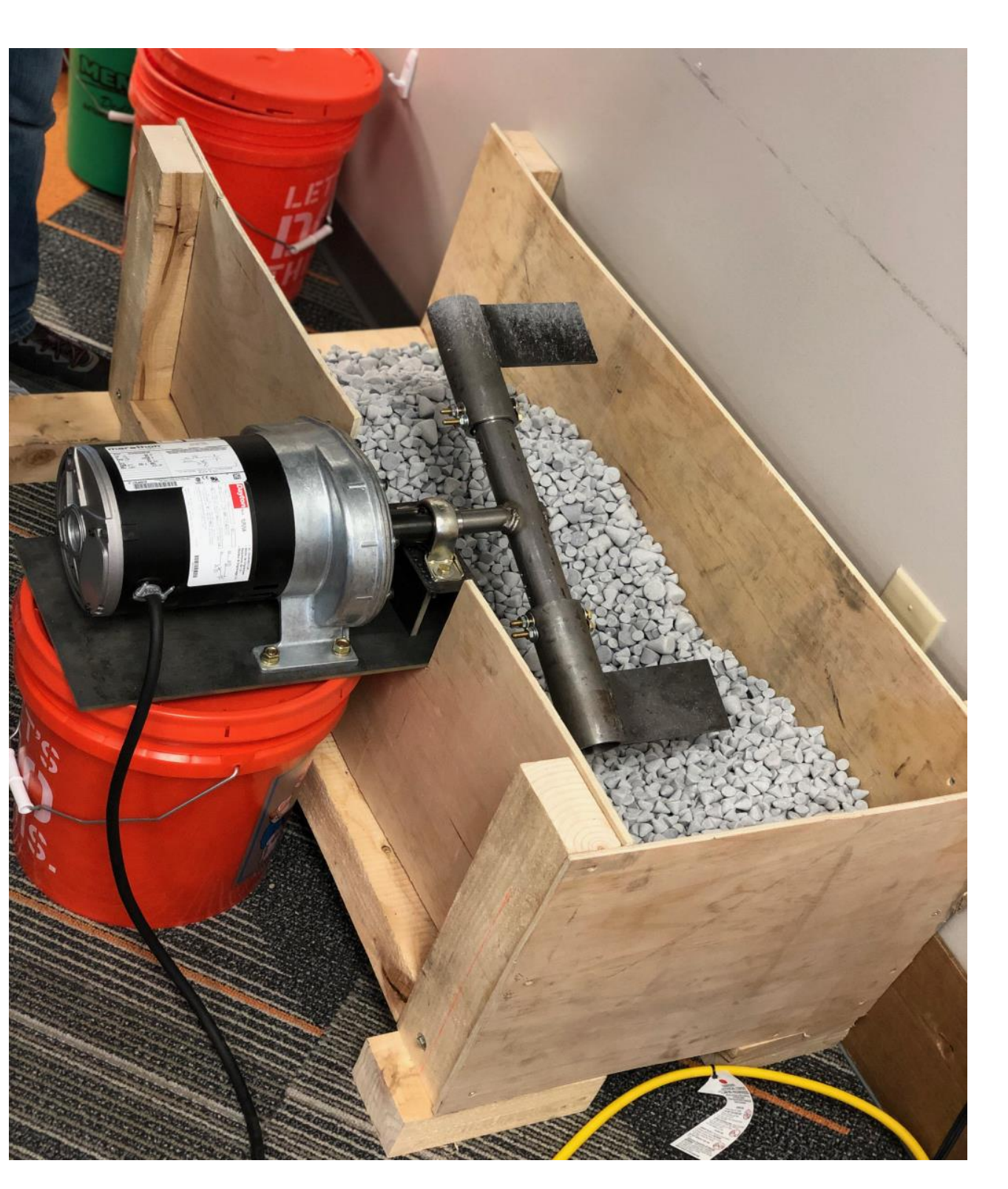

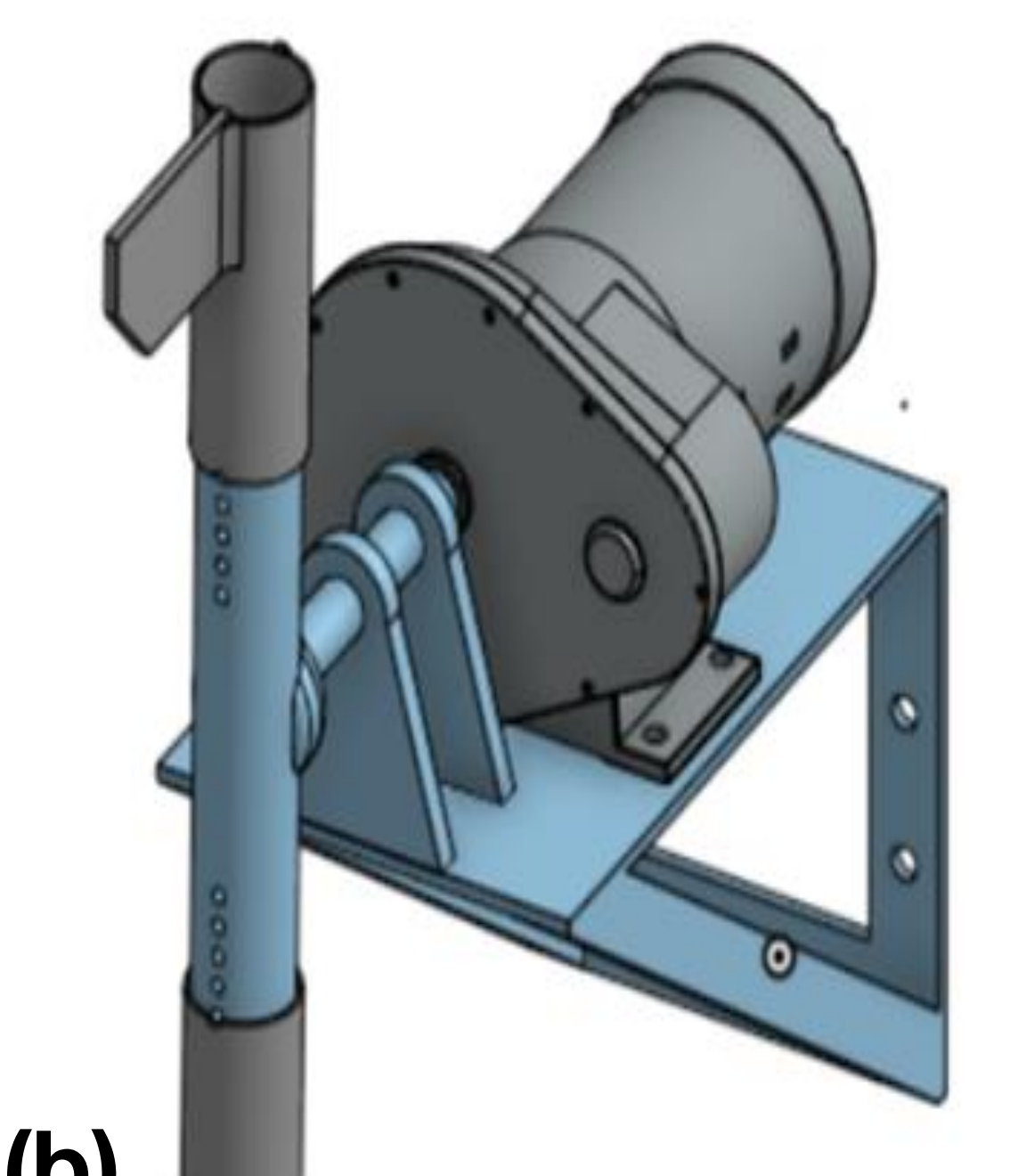

(b)

(a)

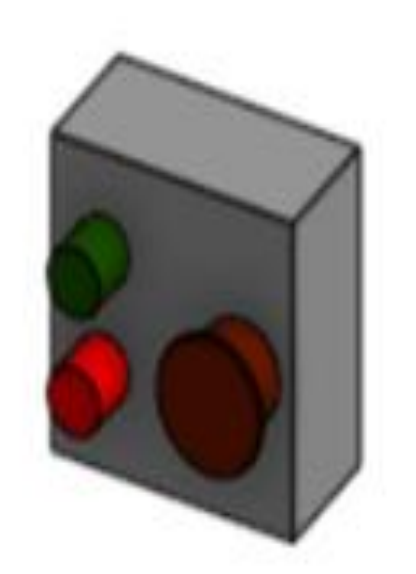

(c)

\section{Testing}

The figure below shows a replica of the hopper to test the fabricated system on campus at the University of Indianapolis. Using media obtained from Yamaha, this will verify that the system sweeps it out at an appropriate amount of time.

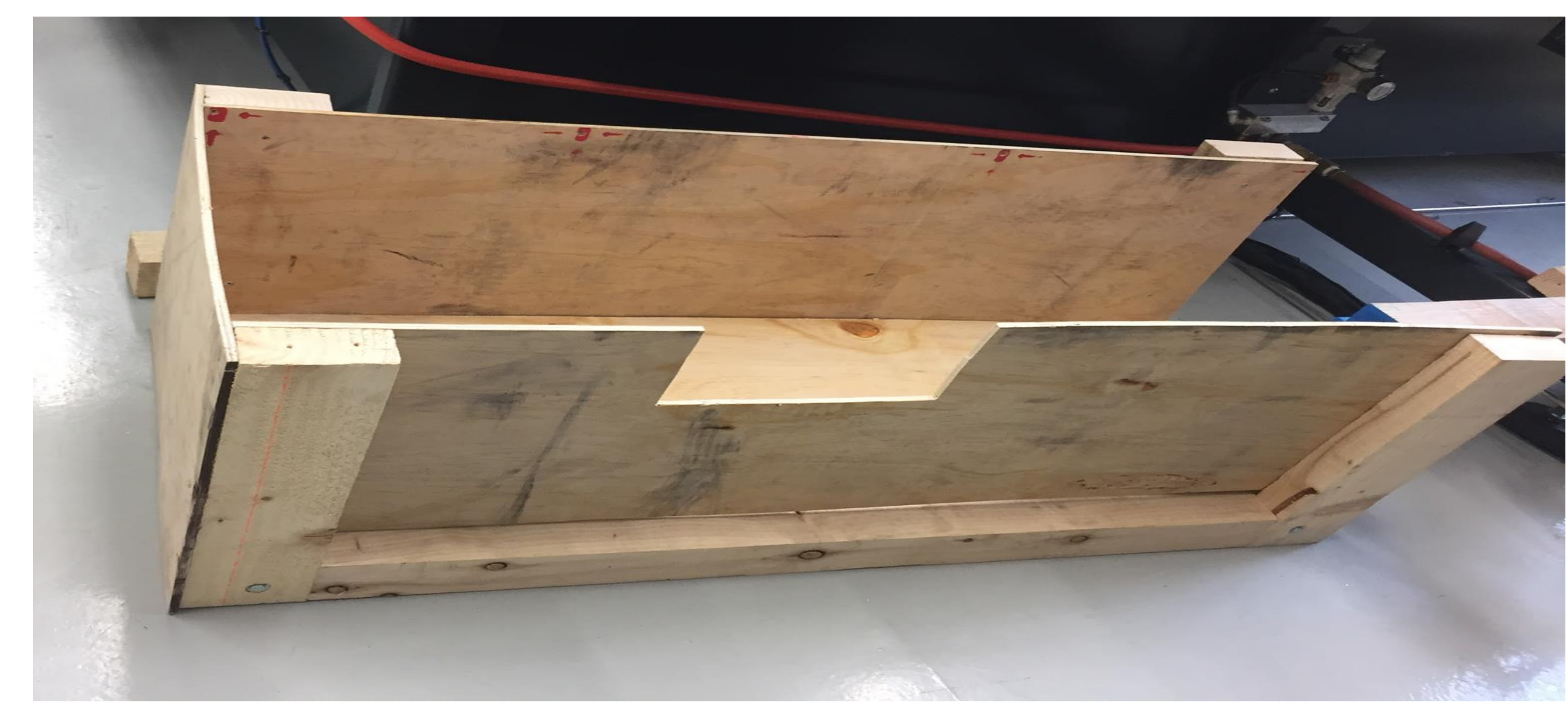

a)

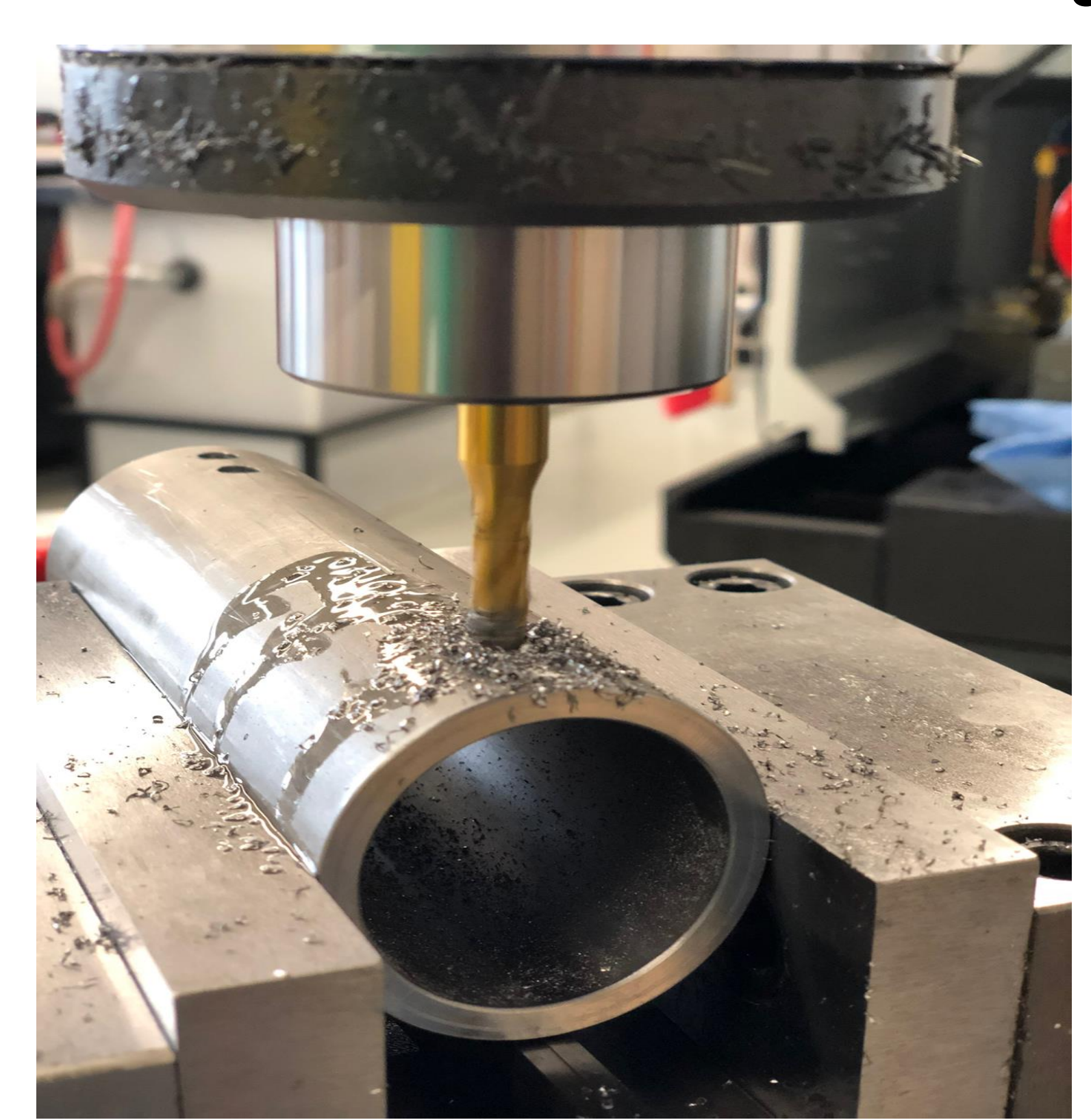

b)

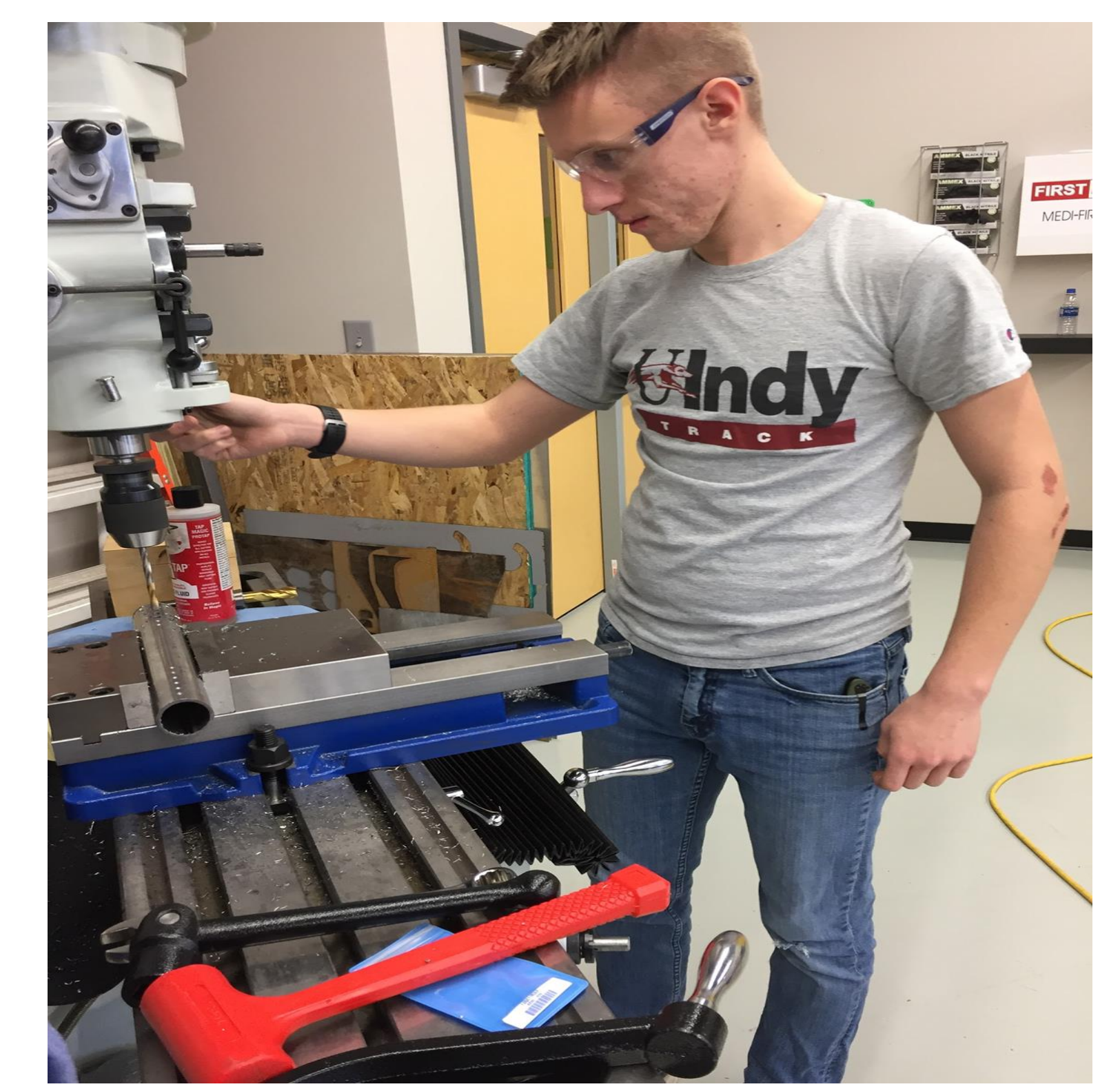

c)

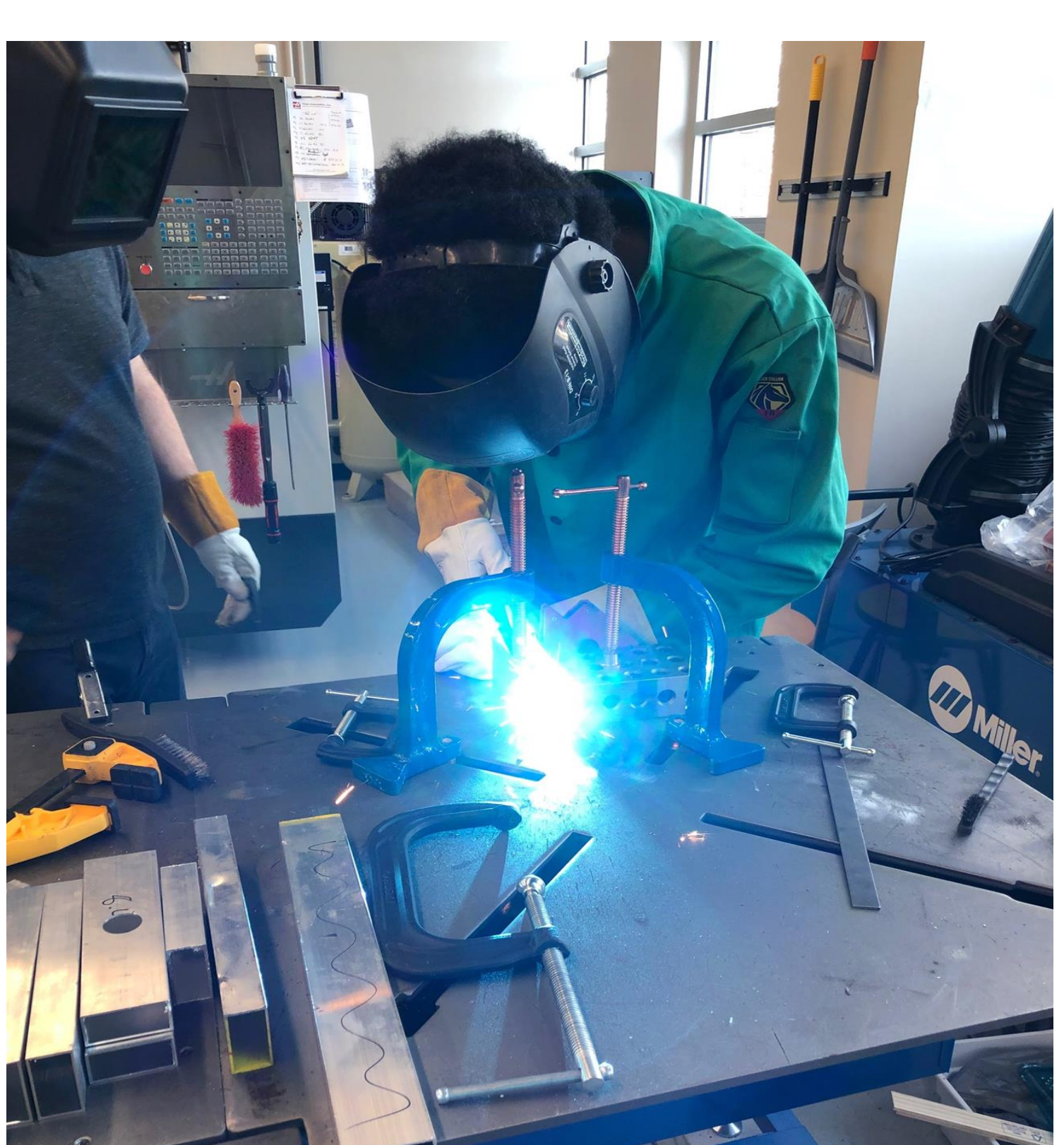

d)

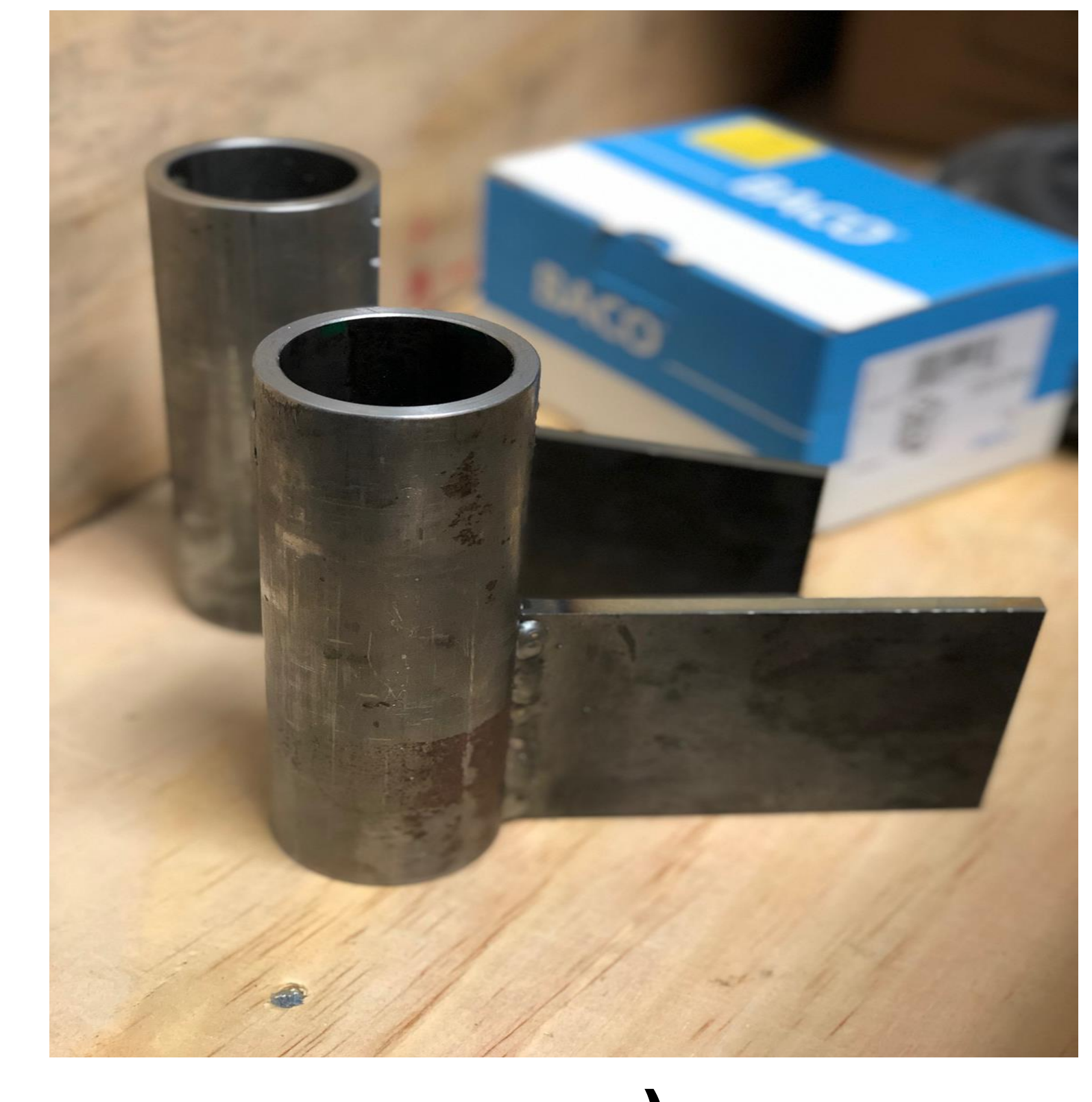

e)
Fig. 3. Manufacture process of the process of the sweeper. a) Replica of hopper fabricated by Kyla Christmas and Muluh J. Tizie for testing. b) Drilling holes on the steel arm.

c) Tyler Cook operating the hole drilling process on the arms. d) Muluh J. Tizie welding together different parts of the system. e) A view of the welded arms.

\section{Optimization of Design}

The team came up with some preliminary designs to solve the problem at Yamaha. The first idea was to use a rubber seal that will incorporated all requirements needed to delegate our assigned task. The second idea was a little complex and required that we redesign a new section of the machine where media was lost. The team's third idea was to create a sweeping system that will remove media out of the hopper at an appropriate time. This design was adopted by the team to solve the problem at Yamaha.

The design has been tested on the replica of the hopper which was fabricated on campus and it works perfectly fine. It obviously does not have all the constraints that the original system has. The parameter needed to be determined to achieve the best performance by our design is to withstand vibration of the original system.
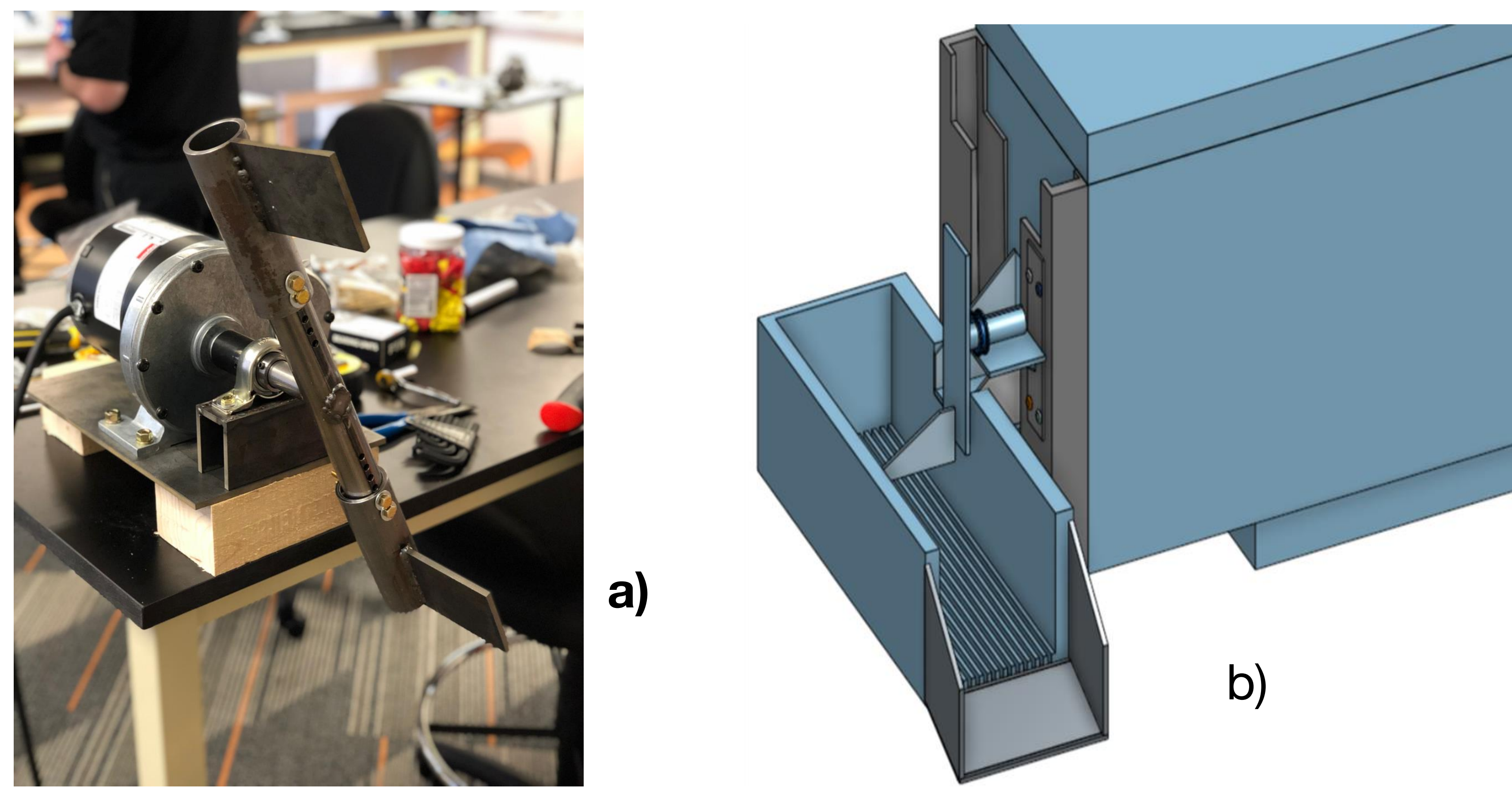

Fig 4: a) a view of the fabricated system, not yet installed on the vibratory machine. b) A drawing of the optimized design, hopper and vibratory system.

\section{Conclusion and Future Work}

The team has created a design, fabricated it, and have tested have tested it on the replica of the hopper which was manufactured at the University of Indianapolis more text here. This test was a success. The next step involves the testing of this product at the Yamaha facility in Indianapolis where there will be more constraints.

\section{Acknowledgements}

This project was supported by the University of Indianapolis R.B. Annis School of Engineering, and we would like to give special thanks to the management of Yamaha Marine Precision Propellers (YMPP), Indianapolis. 